\title{
MANIFESTATIONS OF SYPHILIS AS SEEN IN THE NOSE AND THROAT TO-DAY*
}

\author{
By F. C. W. CAPPS, F.R.C.S.
}

Mr. President, Ladies and Gentlemen,-I have to thank you sincerely for the honour you do me in asking me to open this discussion to-night. I am very conscious that I am unworthy of this honour, for I have no special knowledge or experience of syphilis and can merely offer to you a few observations concerning the occurrence of the disease in patients I have seen in practice, and in the Ear, Nose and Throat Out-Patient Departments of several Londor. General Hospitals during a period of some fifteen years. These occurrences have in the main been few and far between, and I am forced to the conclusion either that these cases do not appear in the ear, nose and throat clinics or that, thanks to the efficient propagation of knowledge by your speciality, improving social conditions, and a greater sense of hygienic responsibility, patients present themselves for treatment at a much earlier stage of the disease. I hope and think that the latter alternative is the more likely and I would that in other branches of medicine we could show such a satisfactory picture.

The early treatment of cancer, for example, is still far more of a hope than a fact. I shall be interested to hear from your members and especially from those at the more special hospitals whether they find a high incidence of lesions in the upper respiratory tract in cases which have not attended for these lesions elsewhere. I am well aware that there are parts of the world where advanced and neglected lesions are still to be found but they seem to be getting very rare in London, and even minor secondary and tertiary manifestations are infrequently seen by myself and such colleagues as I have questioned on the subject.

When I was asked to open this discussion, I limited my scope to the nose, throat and larynx. In the ear, the part played by syphilis is largely neural or due to histological

* Based on an address delivered before the Medical Society for the Study of Venereal Diseases, May 28th, 1937. 


\section{BRITISH JOURNAL OF VENEREAL DISEASES}

changes in the inner ear and presents no macroscopic lesions for inspection. On somewhat similar grounds of inaccessibility, I ruled out the esophagus and trachea. In the last two regions in any case I would have had no single example to quote you.

As a basis of discussion, I propose to enumerate briefly the main lesions we may expect in this region and will continue by relating those I have actually seen. Gerber, of the Königsberg Nose and Throat Clinic, writing in IgIO, states that he found evidence of syphilis in 672 out of a total of 76,663 patients who had attended the clinic, or 0.9 I per cent., 285 were men and 352 women, the remainder evidently children. There were four primary, I05 secondary and 329 tertiary lesions and their distribution was nose 23I, postnasal space 59 , mouth and pharynx 48I, larynx and trachea II 5 and ear 33.

Any personal figures I might tabulate would look ridiculous alongside these, but I am quite certain that the percentage of patients presenting themselves with evidence of syphilis is far smaller than $0.9 \mathrm{I}$ per cent., and probably considerably less than half that figure. The proportions between the various sites appear about the same.

The lesions to be expected are :-

The Nose

\section{In Acquired Syphilis}

(I) Primary chancre of nostril.

Primary chancre of nasal passage - very rare.

(Gaucher in I9Io recorded 3 among Ioo extragenital chancres, and comments on the triviality of their symptoms.)

(2) Secondary-almost unknown, probably an

(3) Tertiary. obstinate coryza.

Gumma.

Ulceration.

Perichonditis and necrosis.

Syphilitic ozœena or atrophic rhinitis.

In all cases the gumma is the foundation of the manifestations.

As a result of syphilitic processes you may get :Stenosis and atresia of vestibules.

Atrophic rhinitis. 


\section{MANIFESTATIONS OF SYPHILIS}

Perforations of palate.

External deformities.

The Pharynx

(I) Primary (not uncommon), usually on the tonsil,

(2) Secondary. occasionally on the palate or pharyngeal wall.

Erythema (avoiding the hard palate).

The mucous patch.

A general hypertrophy of Waldeyer's ring and associated adenopathy.

Although some of these appearances may be characteristic to a trained eye, few clinicians care to make a diagnosis without evidence elsewhere in the body to confirm their suspicions.

(3) Tertiary.

The serpiginous ulcer.

The gumma, single or multiple, in stage of infiltration. Softening or ulceration.

Diffuse gummatous infiltration (may be mistaken for malignant disease).

As a result of tertiary lesions we may get cicatrisation.

Perforations leading to oronasal or oropharyngeal fistulas, adhesions, either as bands or the fusion of whole surfaces, e.g., the adherence of soft palate to pharyngeal wall with partial or even complete occlusion of the postnasal space, and of base of tongue and posterior pharyngeal wall with only a small aperture leading to larynx and hypopharynx.

\section{The Larynx}

(I) Secondary.

(2) Tertiary.

Syphilitic " catarrh" of the larynx.

Gumma.

Ulceration.

Perichonditis and necrosis.

Involvement of recurrent laryngeal nerve and, as a result of these processes,

Induration - or the whole wall or pachydermia of cords.

Scars.

Adhesions. 


\section{BRITISH JOURNAL OF VENEREAL DISEASES}

In Hereditary Syphilis we get secondary and tertiary manifestations :-

The chronic coryza ("snuffles") of the infant, and later-

(I) Destructive ulceration in the nose with necrosis, collapse and cicatrisation.

(2) Gummatous ulceration of pharynx leaving scars and deformities.

(3) and least common, perichonditis, hyperplasia and ulceration (with subsequent cicatrisation) of the larynx.

The question of differential diagnosis is important.

In the nose, lupus, atrophic rhinitis, malignant disease, leprosy and glanders.

Lupus has a slow history and typical lessions are usually present on the skin of the face. No odour.

Leprosy and glanders are rare affections met with either in certain localities (leprosy) or in those associated with infected horses (glanders).

Atrophic rhinitis is nowadays very much more rare than it was thirty years ago. Gaucher in his "Syphilis du Système Nerveux de l'œil de l'oreille et du nez," I9ro, states that ozœna was thought by some to be invariably associated with hereditary syphilis. He argues against this and rightly attributes the atrophic condition more to some trophic disturbance of constitutional origin (of which syphilis might occasionally be the cause). It has always struck me as significant that atrophic rhinitis which more often affected young women has disappeared almost to the same degree as another disease of young women common at that time-chlorosis.

St. Clair Thomson states that " one of the first guiding principles to bear in mind is that necrosis in the nose is almost unknown except in connection with syphilis."

In ozœna there is offensive smell and crusting but the mucosa is seldom ulcerated and the bones are never necrosed.

With regard to the question of dead bone, care must be taken not to mistake for this a foreign body or a rhinolith, both of which are usually associated with ozœna.

Malignant disease in the nose is generally rather proliferative and bleeds very readily. It is more often associated with pain, though gumma may give rise to maddening pain until it breaks down. 


\section{MANIFESTATIONS OF SYPHILIS}

In the mouth and throat pyogenic infections, thrush, Vincent's angina, diphtheria, tuberculosis and malignant disease may all cause doubt. Pyogenic infections are usually bilateral. Thrush is more yellow and surrounded by angry margins. It is painful as is also the ulceration of Vincent's angina. A smear from the latter shows in a Gram film the characteristic association of spirochætes and bacilli. It is well to remember that the spirochata pallida may also be present and it is wise not to treat an ulcer for Vincent's infection too long without having a Wassermann reaction performed. Diphtheria has the characteristic membrane and tubercular ulcers lack the " punched out " appearance and the " wash leather " base and are usually very painful.

It is very characteristic of syphilitic lesions in the throat that although the patient complains of discomfort and may look toxic, yet the constitutional disturbance and local disability and pain are by no means commensurate with the appearance of the throat.

It is well to remember that malignant disease and syphilis in the mouth and pharynx often co-exist and, where in doubt, both a biopsy and a Wassermann reaction should be performed.

In the larynx, tubercle and malignant disease are the chief difficulties in differential diagnosis. The history, the condition of the chest, mobility of the cord and site of the lesion are all important points. Sputum examination, Wassermann and biopsy all play their part in confirming or correcting the clinical diagnosis.

Therapeutic tests so-called are utterly fallacious. All neoplasms improve temporarily with antisyphilitic treatment, particularly potassium iodide.

Pictures and slides were shown illustrating some of these lesions :-

\section{The Nose}

(I) Primary chancre of the nostril.

(2) Ulceration of the nose.

(3) Destruction of the bridge of the nose and sequestration of bone. Repaired with plastic operation.

(4) Congenital syphilis, destruction of the nose, plastic operation repair. Syphilide in repair flap. Pot. Iod. cleared. 


\section{Mouth and Pharynx}

No instances could be shown of primary lesion.

Secondary.-In none of the cases looked through had a typical mucous patch been recorded.

Late Secondary or Early Tertiary Lesions. Serpiginous ulcer which had at the same time a typical papular syphilide.

Serpiginous ulcer of the right tonsil.

Ulceration of the right tonsil, with swelling of the left tonsil.

Large excavated ulcer of the posterior pharyngeal wall of a patient with a strong history of laryngitis and catarrh. When first seen granular pharynx-syphilis not suspected.

Excavated ulcer of the posterior pharyngeal wall.

Case of perforation of the hard palate.

Large ulcer of the posterior pharyngeal wall.

Extensive swelling of the soft palate.

Perforation of the soft palate.

Perforated palate and induration of the left posterior pillar.

\section{Naso-pharynx}

Gummatous ulceration of the upper surface of the soft palate on the left side.

Gummatous ulceration of the upper surface of palate and around Eustachian tube associated with Vincent's angina.

Gummatous ulceration of the upper surface of the uvula which appeared swollen and œdematous from the mouth.

\section{Larynx}

Gummatous ulceration leading later to a laryngeal web.

Hyperkeratosis of one vocal cord causing severe obstruction and requiring tracheotomy. Microscopic section shown.

Illustrations were shown from Gerber's book of typical mucous patches :-

Gumma.

Ulcerated pharynx.

Gumma-hard palate.

Infiltrated tongue.

Condylomata larynx.

Gumma sinus pyriformis. 


\section{MANIFESTATIONS OF SYPHILIS}

\section{CoNCLUSIONS}

The treatment of these cases is, of course, referred to the Venereal Diseases Clinic and where possible it is from their notes that I have been able to record the progress of the cases. I find that patients will not come back to the Throat Clinic for inspection although I have frequently requested that they should, and endeavours have been made by the Sister-in-Charge and the medical officers of the Clinic to get them to come. It is a little disappointing that we cannot see the after results of the lesions we send down and, in future, I am still further going to impress on the patients the importance of their return to my department when their throats are better, so that I may definitely exclude all disease. It will, I think, be definitely necessary to frighten them into thinking that I am the only person who can say when the disease is cured if I am to see the case again.

Before I close, I would like just to touch upon the subject of leukoplakia, not of the tongue because I think this is a well-recognised entity, but we do see in the Throat Department the leukoplaktic patches of the inside of the cheek and on the alveolar process, soft palate and hard palate. I have felt convinced from some cases which I have seen recently that a luetic infection is not the sole cause of this. The dental sepsis is, I think, a potent factor in some cases. That the condition in these regions, as also on the tongue, is pre-cancerous has been proved over and over again. On the tongue I still believe that leukoplakia is pathognomic of syphilis. Mr. Cozens Bailey used to say at Bart.'s that 95 per cent. of cases of chronic superficial glossitis of the tongue are syphilitic, the other 5 per cent. are those which occur in one's friends and relations.

Except for the tongue I do not think we can say that there is a great association of syphilis and malignant disease of the upper respiratory tract. Now and again, of course, we find a positive Wassermann in association with malignant disease, but I believe this to be only a coincidence.

I hope we do not miss any cases of syphilis. The nose would seem to be the region where we might miss secondary manifestations. I do not think we do, but I wonder whether some cases of rhinitis ought to be 


\section{BRITISH JOURNAL OF VENEREAL DISEASES}

referred for dark ground illumination of the nasal secretion. I would value opinions on this point.

I am afraid I have told you this evening nothing which you do not already know, and of which you have probably a greater familiarity than I have myself, but if your wish was to hear from me what cases and how many of them I recognise as needing reference to your department, then perhaps I have satisfied your wishes and I thank you very cordially for your patient attention. 